\title{
A group consensus model for evaluating real estate investment alternatives
}

\author{
Wenshuai Wu $\mathrm{W}^{1,2,4^{*}}$ and Gang $\mathrm{Kou}^{3}$
}

\author{
* Correspondence: fhylwsw@163. \\ com \\ ${ }^{1}$ School of Economics and \\ Management, East China Jiaotong \\ University, Nanchang, Jiangxi \\ 330013, China \\ ${ }^{2}$ Business School, Sichuan \\ University, Chengdu, Sichuan \\ 610065, China \\ Full list of author information is \\ available at the end of the article
}

\begin{abstract}
Background: Individual decision-making largely influences the effectiveness of decisions and benefits of investments. Methods: In this article, a consensus model for group decision-making (GDM), based on the analytic hierarchy process (AHP), is developed to gather group ideas and analyze the real estate investment environment under multi-criteria problems. Twelve evaluation procedures of the developed model, which increase the convergence of the opinions of multiple experts, are proposed.
\end{abstract}

Results: An empirical case about the real estate investment environment is applied to certify the feasibility of this developed model.

Conclusions: the evaluation procedures have been fully observed with several rounds of discussions, and have manifested the experiences of experts. Besides, the evaluation results are in accordance with real-world situations, which demonstrates that our developed model is a feasible analysis tool for real estate investors to obtain better profits and lower risk.

Keywords: Group decision-making, Analytic hierarchy process, Real estate investment, Decision analysis

\section{Background}

Real estate investment is an economic behavior that inputs resources and money to estate development, management and intermediary services in order to obtain the maximum profits. Since there is a high rate of return on investment in the real estate industry, the corresponding market grows rapidly (Hoag, 1980). However, the real estate investment pattern is very different from other investment patterns because of its fixed location, long period, and great value. Besides, real estate investment is more easily affected by economic policy, social needs, market capacity, laws and regulations, etc. Moreover, the risk of real estate investment mainly originates from two aspects (Zietz et al., 2003): (1) the uncertainty of the developers and (2) the influence of the outside environment. Real estate investment environment is the sum of external factors restricting and affecting real estate investment, and people are struggling to make a satisfactory decision in the real estate investment environment, especially in the investment to buy their house. Therefore, there is no doubt that a good investment environment is critical to real estate investors in order to obtain better profits and lower risk.

The investment environment refers to all of the factors that can affect investment patterns. For any real estate investments, investment environment plays an important

(C) 2016 The Author(s). Open Access This article is distributed under the terms of the Creative Commons Attribution 4.0 International License (http://creativecommons.org/licenses/by/4.0/), which permits unrestricted use, distribution, and reproduction in any medium, provided you give appropriate credit to the original author(s) and the source, provide a link to the Creative Commons license, and indicate if changes were made. 
role. Risk evaluation is an important task for real estate investment under a multicriteria environment (Lee et al., 2008). However, how to develop and design an effective model to evaluate the risk of this multi-criteria investment environment is an urgent and challenging problem. And in real estate investment, the decisions are usually made by several family members or groups of experts. To solve this problem, in this article, a consensus model for group decision-making (GDM), based on the analytic hierarchy process (AHP) with several rounds of discussions, is developed to gather group ideas and analyze the real estate investment environment.

The AHP is a decision-making analysis method for structuring hierarchies, measurements, and syntheses (Saaty, 1980). It can convert the views and opinions of decision makers (DMs) into pairwise comparison values, induced and completed by expert scoring (Kamal, 2001). In view of the pairwise comparison values, a relative priority vector, which can express information regarding preferences, can be elicited by the AHP (Liu and Shih, 2005). Therefore, the AHP can assist the DMs in selecting the most satisfactory alternative or forecasting an outcome (Forman and Gass, 2001). Moreover, the AHP is often used to address various kinds of situation problems, such as weight determination, alternative assessment, quality management, resource allocation, and strategic planning (Liberatore, 1987; Cheng and Mon, 1994; Kwong and Bai, 2002; Ahsan and Bartema, 2004; Melón et al., 2008; Hermans and Thissen, 2009; Luca, 2014).

Arbel and Orgler (1990) introduced and described the AHP method to evaluate a strategy for bank mergers and acquisitions, while Ramanathan and Ganesh (1995) applied the AHP to solve the multi-criteria problem of resource allocation, by transforming the multi-criteria problem to a single-objective linear programming problem. In addition, based on the AHP, Tam and Tummala (2001) developed a model to evaluate a vendor of telecommunications system, while Zeki (2005) developed a fuzzy method to evaluate a concept involving new product development. Lee and Kozar (2006) used the AHP to extend a success model of DeLone and McLean's information systems, in order to investigate the factors of website quality. Further, Liberatore and Nydick (2008) reviewed the AHP to help with important decision-making problems in the medical and health care industry, while Amiri (2010) used the AHP to investigate a structure situation involving an investment project.

Under a complex social reality environment, the decision-making process itself has become very complicated. Thus, correct and scientific decision-making is usually very difficult to achieve by only a single DM, because of time pressure and the limitation of the information-processing capacity, expertise, and experience. Therefore, in order to decrease decision mistakes as much as possible, the decisions should be made by multiple DMs. The AHP method is considered suitable for GDM because of its role as a synthesis mechanism (Dyer and Forman, 1992; Wu et al., 2012), where a group of DMs can decompose a complex decision-making problem into a hierarchy construction, according to their expertise and experience, and then deal with it according to the traditional steps of the AHP (Kamal, 2001; Wu et al., 2012). In this model, several rounds of discussions are introduced into the AHP to make the real estate investment decision explicit and accurate by quantifying preferences based on the hierarchy structure.

The remaining sections of this article are organized as follows. In Section 2, some preliminaries are briefly described in order to better understand our proposed consensus model. In Section 3, the consensus model for GDM under a multi-criteria environment is proposed 
and developed. In addition, Section 4 shows an empirical case to illustrate the feasibility of our proposed consensus model. Finally, Section 5 provides some concluding remarks.

\section{Methods: Analytic Hierarchy Process}

The AHP, a widely applied decision analysis technology, was first proposed and developed by Saaty $(1980 ; 1986)$, and it is considered an important tool to address multi-criteria problems (Lai et al., 2002). The AHP combines both the quantitative and qualitative sides to receive an alternatives-related priority vector in a numeric scale (Moreno-Jiménez et al., 2008; Wu et al., 2012). The AHP usually involves three basic functions: (1) decomposition, (2) comparative judgments, and (3) synthesis. It can be supported to calibrate a ratio scale for the measurement of tangible, as well as intangible, aspects (Vaidya and Kumar, 2006; Peng et al., 2011; Deng et al., 2014).

In the AHP, a complex decision problem could be broken down into a hierarchy structure. Based on the pairwise comparison values of the hierarchy structure, a relevant priority vector, which can express information on preferences, can be elicited by the AHP. The calculation steps are illustrated and presented as follows (Saaty, 1990; Kamal and Al-Harbi, 2001; Liu and Shih, 2005; Yu et al., 2011):

(1)Identify the complicated decision problem stated and presented in the topmost level of a hierarchical structure.

(2)Structure the hierarchy. A complex decision problem could be broken down into a hierarchy structure by the AHP (Yu et al., 2011). In the solving process, the typical hierarchy structure usually has three levels: (1) alternative, (2) criteria, and (3) objective, as presented in Fig. 1.

(3) Establish a pairwise comparison judgment decision matrix for every hierarchy level, by expert scoring, according to the scale measurement (Kamal and Al-Harbi, 2001), as presented in Table 1.

(4)Determine the criteria weights, which can be done using the eigenvector method, according to the equation:

$$
A W=\lambda_{\max } w
$$

where $\lambda_{\max }$ is a maximum eigenvalue and $w$ is an eigenvector with regard to $\lambda_{\max }$.

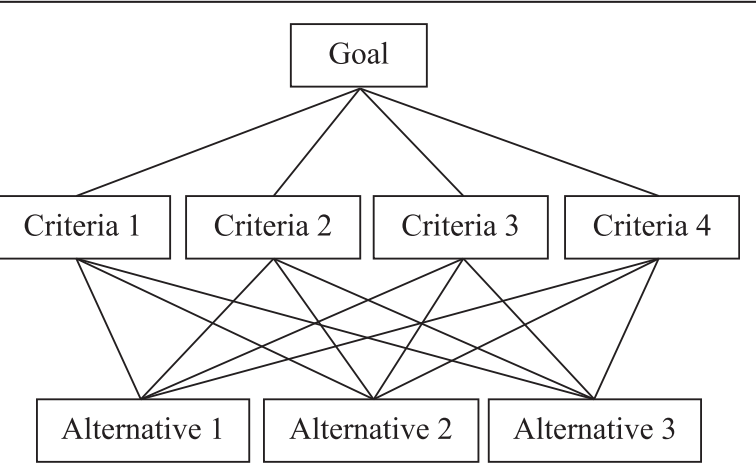

Fig. 1 Hierarchy structure of the AHP 
Table 1 Pairwise comparison scale for AHP preferences (Kamal and Al-Harbi, 2001)

\begin{tabular}{ll}
\hline Numerical rating & Verbal judgments of preferences \\
\hline 9 & Extremely preferred \\
8 & Very strongly to extremely \\
7 & Very strongly preferred \\
6 & Strongly to very strongly \\
5 & Strongly preferred \\
4 & Moderately to strongly \\
3 & Moderately preferred \\
2 & Equally to moderately \\
1 & Equally preferred \\
\hline
\end{tabular}

(5) Test the consistency of the pairwise judgments. The AHP must meet the property the comparison judgment decision matrix is consistent. In addition, the consistency is calculated using two parameters: (1) the consistency index $C I$ and (2) consistency ratio $C R$. These two parameters are defined as follows:

$C I=\frac{\left(\lambda_{\max }-n\right)}{(n-1)}$

$C R=\frac{C I}{R I}$

where $n$ is the size of the pairwise comparison judgment-decision matrix and $R I$ is an average random consistency index. The corresponding values (Liu and Shih, 2005) are revealed in Table 2. If $C R$ does not exceed 0.10, it is acceptable; otherwise, the comparison judgment-decision matrix is inconsistent.

(6)Derive the priority vector of the alternatives. The corresponding priority vector can be derived according to the criteria weights, using the eigenvector method, when the comparison judgment-decision matrix satisfies a consistent matrix.

\section{The proposed consensus model for group decision-making}

The benefits of real estate investment depend not only on the quality of investors but also investment environment, for example, economic policy, social needs and market capacity. For any investments, investment environment plays an important role, and enormous influence on the investors' decision can be created by investment environment. Moreover, in the evaluation of real estate investment environment, the decisions are usually made by several family members or groups of experts. To solve this problem, in this article, a consensus model for GDM with several rounds of discussions, is developed. GDM (Hwang and Lin, 1987) with several rounds of discussions is a dynamic decision method, using the repeated interaction among DMs to seek group consensus. When making group decisions, Hackman and Kaplan (1974) found that the long-lasting conferences would increase costs and reduce

Table 2 Average random consistency index (RI) (Liu and Shih, 2005)

\begin{tabular}{lllllllllll}
\hline Size of matrix & 1 & 2 & 3 & 4 & 5 & 6 & 7 & 8 & 9 & 10 \\
\hline Rl & 0.00 & 0.00 & 0.58 & 0.9 & 1.12 & 1.24 & 1.32 & 1.41 & 1.45 & 1.49 \\
Size of matrix & 11 & 12 & 13 & 14 & 15 & & & & & \\
Rl & 1.52 & 1.54 & 1.56 & 1.58 & 1.59 & & & & \\
\hline
\end{tabular}




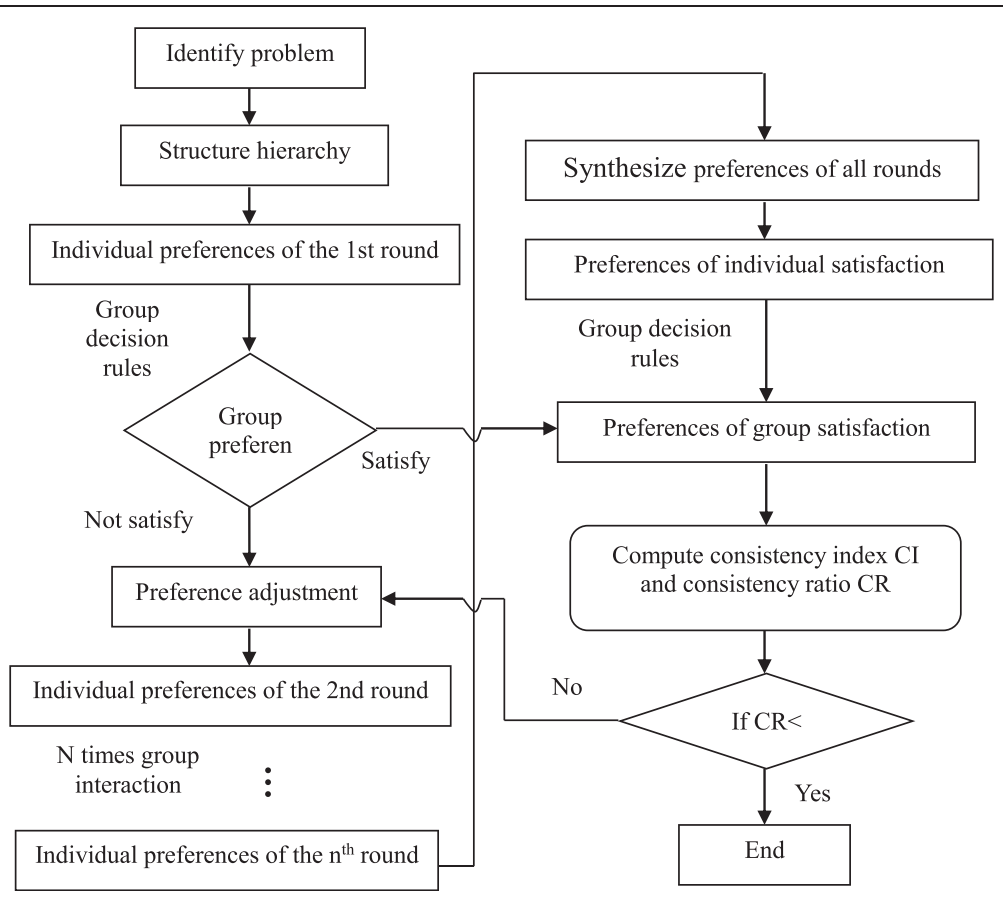

Fig. 2 Evaluation flow chart of the proposed consensus model

the satisfaction of the groups. At the same time, the preferences from the previous round of negotiations, in their own view, can reflect the most suitable program. Achievement of consensus is a critical and core process in the scenario of GDM. Most of the GDM problems are very complex because of the multi-criteria framework related to many subjective and objective factors (Choudhury et al., 2006). The AHP has been considered an important analysis method to deal with the problems arising from GDM (Wu et al., 2012). Besides, decision-making is a complex interdisciplinary process. Moreover, the investment environment can be influenced by many factors, such as the economy, social demands, market volume, policies, and laws. Therefore, this article develops a consensus model for GDM under a multi-criteria environment with several rounds of discussions to gather group ideas. After

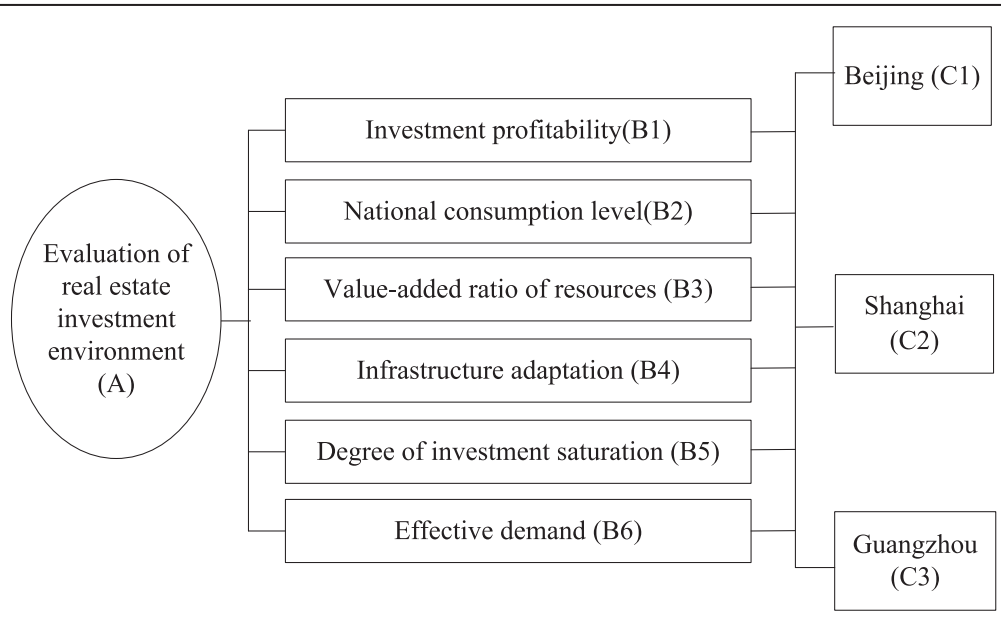

Fig. 3 Decision hierarchy structure 
Table 3 B-A level group comparison matrix, criteria weights, and consistency test

\begin{tabular}{lllllllll}
\hline B-A & $\mathrm{B}_{1}$ & $\mathrm{~B}_{2}$ & $\mathrm{~B}_{3}$ & $\mathrm{~B}_{4}$ & $\mathrm{~B}_{5}$ & $\mathrm{~B}_{6}$ & $W$ & Consistency test \\
\hline $\mathrm{B}_{1}$ & 1 & 3 & 3 & 5 & 3 & $1 / 3$ & 0.2701 & $\lambda_{\max }=6.405$ \\
$\mathrm{~B}_{2}$ & $1 / 3$ & 1 & 3 & 3 & 2 & $1 / 2$ & 0.1603 & CR $=0.065<0.1$ \\
$\mathrm{~B}_{3}$ & $1 / 3$ & $1 / 3$ & 1 & $1 / 2$ & $1 / 2$ & $1 / 4$ & 0.0582 & \\
$\mathrm{~B}_{4}$ & $1 / 5$ & $1 / 3$ & 2 & 1 & 1 & $1 / 3$ & 0.0799 & \\
$\mathrm{~B}_{5}$ & $1 / 3$ & $1 / 2$ & 2 & 1 & 1 & $1 / 2$ & 0.0984 & \\
$\mathrm{~B}_{6}$ & 3 & 2 & 4 & 3 & 2 & 1 & 0.3330 & \\
\hline
\end{tabular}

each round of discussion, DMs are allowed to revise their preferences in order to better reflect their level of agreement on the issues.

The implementation process for the consensus model for GDM is detailed as follows.

Step 1. Identify a goal problem. The goal problem is usually declared in the objective level of a hierarchy, which can be broken down into different criteria and alternative levels.

Step 2. Structure a hierarchy. The hierarchy is composed of alternative, criteria, and objective levels, and includes a list of all of the alternatives.

Step 3. Select an appropriate group of experts who are familiar with the research problem.

Step 4. Determine the individual preferences of the first round. Construct a pairwise comparison matrix, using a 1-9 scale measurement, according to expert scoring. Experts are asked to suggest the appropriate prioritization of the ideas, and ideas with low rank are eliminated.

Step 5. Integrate group preferences using group decision rules. The geometric and arithmetic mean methods are considered commonly used decision rules to integrate group preferences. When multiple experts are satisfied with the group preference, the consensus process is over. In other words, if a group preference is obtained, one can skip right to Step 10; otherwise, one should proceed to the next step.

Step 6. Adjust preferences. Reconstruct a pairwise comparison matrix according to expert scoring.

Step 7. Determine the individual preferences from the second round. The prioritization of ideas is suggested by expert discussion; the ideas with the lowest ranking should be eliminated.

Step 8. Repeat Steps 4-7 until the group preference satisfies multiple experts. The aim is to find the best satisfactory solution that enhances the overall level of satisfaction for the group of DMs.

Step 9. Synthesize the preferences of all rounds, using group decision rules to get the preferences of individual satisfaction.

Table 4 C- $B_{1}$ level group comparison matrix, criteria weights, and consistency test

\begin{tabular}{llllll}
\hline$C-B_{1}$ & $C_{1}$ & $C_{2}$ & $C_{3}$ & $W$ & Consistency test \\
\hline$C_{1}$ & 1 & $1 / 4$ & 3 & 0.2255 & $\lambda_{\max }=3.083$ \\
$C_{2}$ & 4 & 1 & 5 & 0.6740 & $C R=0.080<0.1$ \\
$C_{3}$ & $1 / 3$ & $1 / 5$ & 1 & 0.1004 & \\
\hline
\end{tabular}


Table 5 C- $B_{2}$ level group comparison matrix, criteria weights, and consistency test

\begin{tabular}{llllll}
\hline$C-B_{2}$ & $C_{1}$ & $C_{2}$ & $C_{3}$ & $W$ & Consistency test \\
\hline$C_{1}$ & 1 & $1 / 3$ & 2 & 0.2380 & $\lambda_{\max }=3.015$ \\
$C_{2}$ & 3 & 1 & 4 & 0.6254 & $C R=0.015<0.1$ \\
$C_{3}$ & $1 / 2$ & $1 / 4$ & 1 & 0.1366 & \\
\hline
\end{tabular}

Step 10. Calculate the preferences of group satisfaction with several rounds of discussions by integrating the individual preferences of each DM.

Step 11. Assess the judgment consistency. The judgment consistency is tested using the consistency ratio $C R$. If $C R$ does not exceed 0.10, it is acceptable; otherwise, the comparison judgment-decision matrix is inconsistent. Usually, the judgments need to be revised and improved to get a consistent matrix.

Step 12. Compute the criteria weights using the eigenvector method to derive the relative priorities among evaluation alternatives.

In this paper, the specific and detailed evaluation flow chart of the proposed consensus model for GDM, with several rounds of discussions, is proposed and presented in Fig. 2.

\section{Empirical study}

In this section, an empirical case about the evaluation of the real estate investment environment is tested and illustrated to verify the proposed consensus model. Research on the investment environment began in the 1960s, and there are many widely accepted evaluation methods (Henisz, 2000; Lu and Yang, 2007). However, decisionmaking is a complex interdisciplinary process. Reeves and Bordetski (1995) found that DMs are not always able to accurately express their preferences, and in order to make group preference stable and accurate, several rounds of preference adjustment is essential, to synthesize the views and information of the different DMs. Therefore, this article proposes a consensus model for GDM with several rounds of discussions to evaluate the real estate investment environment. In the evaluation problem of the real estate investment environment with several rounds of discussions, the group interaction produced in each round illustrates how DMs vary their preference information with regard to each alternative (Turón et al., 2008).

In the decision hierarchy structure, there are three levels for the evaluation of the real estate investment environment, as presented in Fig. 3. The goal of the decision-making process is explained as follows. The first level, also called the objective level, is Evaluation of real estate investment environment (A). The criteria level of the hierarchy structure is the second level, which includes Investment profitability (B1), National consumption level (B2), Value-added ratio of resources (B3), Infrastructure adaptation (B4), Degree of investment saturation (B5), and Effective demand (B6). The last level is

Table 6 C- $B_{3}$ level group comparison matrix, criteria weights, and consistency test

\begin{tabular}{llllll}
\hline$C-B_{3}$ & $C_{1}$ & $C_{2}$ & $C_{3}$ & $W$ & Consistency test \\
\hline$C_{1}$ & 1 & 2 & $1 / 5$ & 0.1865 & $\lambda_{\max }=3.094$ \\
$C_{2}$ & $1 / 2$ & 1 & $1 / 4$ & 0.1265 & $C R=0.090<0.1$ \\
$C_{3}$ & 5 & 4 & 1 & 0.6870 & \\
\hline
\end{tabular}


Table 7 C- $B_{4}$ level group comparison matrix, criteria weights, and consistency test

\begin{tabular}{llllll}
\hline$C-B_{4}$ & $C_{1}$ & $C_{2}$ & $C_{3}$ & $W$ & Consistency test \\
\hline$C_{1}$ & 1 & $1 / 2$ & 3 & 0.3326 & $\lambda_{\max }=3.047$ \\
$C_{2}$ & 2 & 1 & 3 & 0.5286 & $C R=0.045<0.1$ \\
$C_{3}$ & $1 / 3$ & $1 / 3$ & 1 & 0.1388 & \\
\hline
\end{tabular}

the investment alternative level, which includes Beijing (C1), Shanghai (C2) and Guangzhou (C3).

Results and discussion The specific evaluation procedures regarding the real estate investment environment are introduced and presented in detail, to verify the proposed consensus model, and are as follows.

(1)Identify a goal problem for the evaluation of the real estate investment environment using the (previously mentioned) Step 1.

(2) Structure a hierarchy, which is composed of the alternative, criteria, and objective levels, and contains the list of alternatives, using Step 2, as shown in Fig. 3.

(3) Select five domain experts who are familiar with the real estate investment environment to construct groups of DMs, according to Step 3.

(4) Calculate the preferences of group satisfaction, using Steps 4-11 of our proposed consensus support model. We apply the arithmetic mean method as group decision rules to integrate expert preference. The results of each level of the group comparison matrix, criteria weights, and consistency tests are computed, as displayed in Tables 3, 4, 5, 6, 7, 8 and 9.

(5)Determine the priorities among the alternatives using Step 12. The relative priorities among alternatives can be easily derived by the eigenvector method. The evaluation results of Beijing, Shanghai, and Guangzhou are 0.2514, 0.2958, and 0.1306 , respectively.

From the empirical case, we can draw the conclusion that the real estate investment environment of Shanghai is the best, followed by that of Beijing; thus, the worst investment environment is Guangzhou. The evaluation procedures have been fully observed with several rounds of discussions, and have manifested the experiences and expertise of experts. In addition, the proposed consensus model for GDM gathers group ideas, analyzes the real estate investment environment under multi-criteria problems, and can find the best satisfactory solution, which increases the level of overall satisfaction in the final decision. Further, the results, being consistent with real-world situations, illustrate the feasibility of our proposed consensus model.

Table 8 C- $B_{5}$ level group comparison matrix, criteria weights, and consistency test

\begin{tabular}{llllll}
\hline $\mathrm{C}-\mathrm{B}_{5}$ & $\mathrm{C}_{1}$ & $\mathrm{C}_{2}$ & $\mathrm{C}_{3}$ & W & Consistency test \\
\hline $\mathrm{C}_{1}$ & 1 & 3 & 4 & 0.6150 & $\lambda_{\max }=3.068$ \\
$\mathrm{C}_{2}$ & $1 / 3$ & 1 & 3 & 0.2679 & $\mathrm{CR}=0.066<0.1$ \\
$\mathrm{C}_{3}$ & $1 / 4$ & $1 / 3$ & 1 & 0.1171 & \\
\hline
\end{tabular}


Table 9 C- $B_{6}$ level group comparison matrix, criteria weights, and consistency test

\begin{tabular}{llllll}
\hline$C_{-} B_{6}$ & $C_{1}$ & $C_{2}$ & $C_{3}$ & $W$ & Consistency test \\
\hline$C_{1}$ & 1 & 2 & $1 / 6$ & 0.1632 & $\lambda_{\max }=3.091$ \\
$C_{2}$ & $1 / 2$ & 1 & $1 / 5$ & 0.1087 & $C R=0.087<0.1$ \\
$C_{3}$ & 6 & 5 & 1 & 0.7282 & \\
\hline
\end{tabular}

\section{Conclusions}

In this paper, under a multi-criteria environment, a consensus model for GDM, based on the AHP with several rounds of discussions, is proposed for evaluating real estate investment. In our proposed model, the decision-making process with several rounds of discussions is introduced into the AHP, to develop a dynamic decision-making method that considers group interaction, which is characterized by the utilization of each round of preference information, as well as continuous preference adjustment. Therefore, this model can facilitate the solution of unstructured problems by a group of DMs, increase the convergence of the opinions of multiple experts, and reveal the preference information of each round of the interaction process. An empirical case presented that the evaluation results are in accordance with real-world situations, which demonstrates that our proposed model is a feasible analysis tool to aid real estate developers in real estate investment projects.

The main limitation of this paper is that it focuses on AHP with several rounds of discussions for GDM, which is lack of generalizability. Future research could develop and design other multi-criteria decision making methods with several rounds of discussions for GDM to increase quickly and effectively the convergence of the opinions of multiple experts.

\section{Acknowledgements}

This research has been partially supported by 2016 Soft Science Research Project of Jiangxi Province(\#20161BBA10081), Scientific research start-up project(\#2003414092), Science and technology project of Department of Education of Jiangxi Province( \#GJJ150512), Major project of Education Science "Thirteen Five" Planning Project of Jiangxi Province( \#16ZD019), Grants from the National Natural Science Foundation of China (\#71433001).

\section{Authors' contribution}

The main contributions of Wenshuai Wu are literature research, experimental studies and data analysis, and the main contributions of Gang Kou are manuscript preparation and experimental studies.

\section{Authors' information}

Wenshuai Wu is a teacher in School of Economics and Management, East China Jiaotong University and a post-doctor in Business School, Sichuan University. His research interests are in Multiple Criteria Decision Making, Data Mining and Financial Engineering. He has published more than ten papers in international journals and conferences.

Gang Kou is a professor of School of Business Administration, Southwestern University of Finance and Economics and managing editor of International Journal of Information Technology \& Decision Making. He has participated in various data mining projects, including data mining for software engineering, network intrusion detection, health insurance fraud detection and credit card portfolio analysis. His research interests are in Data mining, Multiple Criteria Decision Making and Information management. He has published more than eighty papers in various peer-reviewed journals and conferences.

\section{Competing interest}

All of the authors have approved the manuscript and agreed with submission to your esteemed journal. There are no conflicts of interest to declare.

\section{Author details}

${ }^{1}$ School of Economics and Management, East China Jiaotong University, Nanchang, Jiangxi 330013, China. ${ }^{2}$ Business School, Sichuan University, Chengdu, Sichuan 610065, China. ${ }^{3}$ School of Business Administration, Southwestern University of Finance and Economics, Chengdu, Sichuan 611130, China. ${ }^{4}$ Changbei Economic and Technological Development Zone, No. 808, East Shuanggang Street, Nanchang, Jiangxi 330013, China. 


\section{References}

Ahsan MK, Bartema J (2004) Monitoring healthcare performance by analytic hierarchy process: a developing country perspective. Int Trans Oper Res 11:465-478

Amiri MP (2010) Project selection for oil-fields development by using the AHP and fuzzy TOPSIS methods. Expert Syst Appl 37(9):6218-6224

Arbel A, Orgler YE (1990) An application of the AHP to bank strategic planning: the mergers and acquisitions process. Eur J Oper Res 48(1):27-37

Cheng CH, Mon DL (1994) Evaluating weapon system by analytic hierarchy process based on fuzzy scales. Fuzzy Sets Syst 63:1-10

Choudhury AK, Shankar R, Tiwari MK (2006) Consensus-based intelligent group decision-making model for the selection of advanced technology. Decis Support Syst 42(3):1776-1799

Deng X, Hu Y, Deng Y, Mahadevan S (2014) Supplier selection using AHP methodology extended by D numbers. Expert Syst Appl 41(1):156-167

Dyer RF, Forman EH (1992) Group decision support with the analysis hierarchy process. Decision Support System 8:99-124

Forman EH, Gass SI (2001) The analytic hierarchy process-an exposition. Oper Res 49(4):469-486

Hackman JR, Kaplan RE (1974) Interventions into group process: an approach to improving the effectiveness of groups. Decis Sci 5:459-480

Henisz WJ (2000) The institutional environment for multinational investment. J Law Econ Org 16(2):334-364

Hermans LM, Thissen WAH (2009) Actor analysis methods and their use for public policy analysts. Eur J Oper Res 196(2):808-818

Hoag JW (1980) Towards indices of real estate value and return. J Financ 35(2):569-580

Hwang CL, Lin MJ (1987) Group Decision Making Under Multiple Criteria: Methods and Applications. Springer, Berlin

Kamal M, Al-Harbi AS (2001) Application of the AHP in project management. Int J Proj Manag 19:19-27

Kwong CK, Bai H (2002) A fuzzy AHP approach to the determination of importance weights of customer requirements in quality function deployment. J Intell Manuf 13:367-377

Lai VS, Wong BK, Cheung W (2002) Group decision making in a multiple criteria environment: a case using the AHP in software selection. Eur J Oper Res 137(1):134-144

Lee Y, Kozar KA (2006) Investigating the effect of website quality on e-business success: an analytic hierarchy process approach. Decis Support Syst 42(3):1383-1401

Lee ML, Lee MT, Chiang K (2008) Real estate risk exposure of equity real estate investment trusts. J Real Estate Finance Econ 36(2):165-181

Liberatore MJ (1987) An extension of the analytic hierarchy process for industrial R\&D project selection and resource allocation. IEEE Trans Eng Manag 34(1):12-18

Liberatore MJ, Nydick RL (2008) The analytic hierarchy process in medical and health care decision making: a literature review. Eur J Oper Res 189:194-207

Liu DR, Shih YY (2005) Integrating AHP and data mining for product recommendation based on customer lifetime value. Inf Manage 42:387-400

Lu CS, Yang CC (2007) An evaluation of the investment environment in international logistics zones: a Taiwanese manufacturer's perspective. Int J Prod Econ 107(1):279-300

Luca SD (2014) Public engagement in strategic transportation planning: an analytic hierarchy process based approach. Transp Policy 33:110-124

Melón MG, Beltran PA, Cruz MCG (2008) An AHP-based evaluation procedure for Innovative Educational Projects: a face-to-face vs. Computer-mediated case study. Omega 36(5):754-765

Moreno-Jiménez JM, Aguaón J, Escobar MT (2008) The core of consistency in AHP-group decision making. Group Decis Negot 17:249-265

Peng Y, Kou G, Wang G, Wu W, Shi Y (2011) Ensemble of software defect predictors: an AHP-based evaluation method. Int J Inf Technol Decis Making 10(1):187-206

Ramanathan R, Ganesh LS (1995) Using AHP for resource allocation problems. Eur J Oper Res 80(2):410-417

Reeves GR, Bordetski A (1995) A frame work for interactive multiple criteria group decision support. Group Decis Negot 4:107-115

Saaty TL (1980) The Analytic Hierarchy Process. McGraw-Hill, New York

Saaty TL (1986) Axiomatic foundation of the analytic hierarchy process. Manag Sci 32(7):841-855

Saaty TL (1990) How to make a decision: the analytic hierarchy process. Eur J Oper Res 48:9-26

Tam MCY, Tummala VMR (2001) An application of the AHP in vendor selection of a telecommunications system. Omega 29(2):171-182

Turón A, Moreno-Jiménez JM, Toncovich A (2008) Group decision making and graphical visualization in e-Cognocracy. Computación y Sistemas 12(2):183-191

Vaidya OS, Kumar S (2006) Analytic hierarchy process: an overview of applications. Eur J Oper Res 169:1-29

Wu W, Kou G, Peng Y, Ergu D (2012) Improved AHP-group decision making for investment strategy selection. Technol Econ Dev Econ 18(2):299-316

Yu X, Guo S, Guo J, Huang X (2011) Rank B2C e-commerce websites in e-alliance based on AHP and fuzzy TOPSIS. Expert Syst Appl 38:3550-3557

Zeki A (2005) A fuzzy AHP-based simulation approach to concept evaluation in a NPD environment. IIE Trans 37(9):827-842 Zietz EN, Sirmans SG, Friday SH (2003) The environment and performance of real estate investment trusts. J Real Estate Portfolio Manage 9(2):127-165 